\title{
Cor e propriedades mecânicas de algumas argilas do Rio Grande do Norte para uso em cerâmica branca
}

\section{(Color and mechanical properties of some clays found in Rio Grande do Norte State for whiteware)}

\author{
M. A. F. Melo, S. G. Neto, D. M. A. Melo, L. P. Carvalho, J. N. Galdino, S. A. G. Silva \\ Departamento de Engenharia Química / Departamento de Química \\ Universidade Federal do Rio Grande do Norte - Campus Universitário \\ Av. Sen. Salgado Filho, 2000 Lagoa Nova, Natal, 59072-970 RN \\ dmelo@matrix.com.br
}

\section{Resumo}

O interesse crescente no uso de argilas para a produção de cerâmica no Rio Grande do Norte requer a caracterização técnica das matérias primas. Este trabalho mostra algumas propriedades de cinco argilas encontradas nesta região, tais como coloração após queima a $950{ }^{\circ} \mathrm{C}$, $1250^{\circ} \mathrm{C}$ e $1450^{\circ} \mathrm{C}$, retração linear e resistência à flexão. A queima de argilas regionais resultaram em uma variedade de faixas de tonalidades do branco ao creme. As propriedades gerais dos produtos da queima são melhores que as reportadas na literatura, demonstrando o potencial tecnológico das argilas da região estudada.

Palavras-chave: cerâmica branca, caracterização, queima.

Abstract

The growing interest in the use of clay minerals for the production of whiteware in Rio Grande do Norte demands the technological characterization of local raw materials. The present study reports some properties of five different clay minerals found in the region, such as tone upon firing at $950^{\circ} \mathrm{C}, 1250^{\circ} \mathrm{C}$ and $1450^{\circ} \mathrm{C}$, linear shrinkage and flexural strength. Firing regional clays resulted in a variety of ranging from white to cream. The overall properties of the resulting products exceeded literature values, showing the technological potential of the regional clays investigated herein.

Keywords: whiteware, characterization, calcination.

\section{INTRODUÇÃO}

As indústrias cerâmicas do Brasil geralmente estão localizadas em determinadas regiões por uma combinação de fatores que envolvem as matérias primas, energia e mercado consumidor. O Rio Grande do Norte segue também a esse conjunto de fatores, tornando-se bastante promissor para o desenvolvimento do setor de cerâmica branca, pois além de energia de baixo custo (gás natural), é detentor de reservas de matérias primas em qualidade e quantidade suficiente para exploração econômica

A indústria cerâmica é uma indústria de processo químico onde as matérias primas (argilas, caulins, quartzo, feldspatos) são processadas em uma seqüência operacional que, a cada etapa, altera suas características físicas e químicas para se obter um produto final com as características de mercado. As etapas fundamentais do processamento cerâmico envolvem: preparo da matéria prima, conformação e processamento térmico (secagem e queima).

O preparo adequado das matérias primas melhora sua conformação e manuseio a cru, garantindo também melhorias no produto após a queima.

A conformação envolve quatro processos (colagem, extrusão, prensagem e plástica), que vai depender da forma geométrica do objeto a ser produzido.

O processamento térmico pode ocorrer em várias etapas do processo cerâmico, mas sua maior importância está relacionada com a secagem e queima. Na secagem ocorre a eliminação de água livre e o corpo adquire resistência mecânica para a queima, evitando problemas de trinca e contrações diferenciais. Controla-se nesta etapa a temperatura, umidade e velocidade.

No processo de queima controla-se o pré-aquecimento, cozimento e resfriamento, com levantamento de curvas de queima que possibilitará estudar os fenômenos físicos e químicos que determinam as características do produto final, como cor, resistência mecânica, absorção, etc..

Este trabalho objetiva a verificação das características físicomecânicas de argilas do Rio Grande do Norte para uso em cerâmica branca.

\section{MATERIAIS EMÉTODOS}

Foram utilizadas quatro amostras de argilas de várias microregiões do Rio Grande do Norte e uma amostra padrão de São Simão, SP, denominadas AM-01 (SP), AM-02, AM-03, AM04 e AM-05, todas apresentando coloração cinza. 
Com a redução da umidade em torno de $8 \%$, através de présecagem natural e em estufa a $110^{\circ} \mathrm{C}$, as amostras foram beneficiadas em moinho de bolas a 100 mesh e acondicionadas em sacos de polietileno. Após peneiramento, as argilas foram misturadas com água para se obter o teor ideal de umidade para prensagem, homogeneizadas e conformadas em prensa hidráulica na pressão de $200 \mathrm{~kg} / \mathrm{cm}^{2}$. Os corpos de prova assim obtidos, foram secos a $110^{\circ} \mathrm{C}$ até massa constante e queimados em forno estático às temperaturas de $950{ }^{\circ} \mathrm{C}, 1250^{\circ} \mathrm{C}$ e $1450^{\circ} \mathrm{C}$ por duas horas.

Após secagem dos corpos de prova a $110^{\circ} \mathrm{C}$, foram feitas medidas de cor, umidade de prensagem, retração linear e tensão de ruptura. Para os corpos queimados além dessas características, mediu-se a absorção em água, porosidade e massa específica aparente. Um fluxograma genérico é apresentado na Fig. 1.

\section{RESULTADOS E DISCUSSÃO}

Os resultados de cor, retração linear, absorção em água, porosidade aparente, massa específica aparente e tensão de ruptura à flexão, estão contidos na Tabela I.
Quanto a cor, verificou-se que os corpos de prova após queima a $950{ }^{\circ} \mathrm{C} \mathrm{e} 1250{ }^{\circ} \mathrm{C}$ para todas as amostras, apresentam variação do creme claro ao branco, o que evidencia teores baixos de ferro, titânio ou manganês em quantidades insuficientes para promover cor no produto final.

$\mathrm{Na}$ temperatura de $1450{ }^{\circ} \mathrm{C}$, as amostras AM-01, AM-02 e AM-03 apresentaram cores variando do creme ao creme claro, enquanto que nas amostras AM-04 e AM-05 observou-se coloração marron, o que mostra influência da temperatura de queima na cor. Com relação a cor após a queima, todas as amostras estudadas se prestam para uso em cerâmica branca, principalmente para produtos queimados na faixa de $1200^{\circ} \mathrm{C}$ a $1300{ }^{\circ} \mathrm{C}$ (azulejos, louça de mesa, pastilhas de revestimento, etc.).

Os ensaios cerâmicos de retração linear (\%), porosidade aparente (\%), absorção de água (\%), massa específica aparente $\left(\mathrm{g} / \mathrm{cm}^{3}\right)$ e tensão de ruptura à flexão $\left(\mathrm{kg} / \mathrm{cm}^{2}\right)$, serão comparados, inclusive a amostra referência, com os dados obtidos por Souza Santos [5], em argilas padrões brasileiras após a queima a $950^{\circ} \mathrm{C}, 1250^{\circ} \mathrm{C}$ e $1450^{\circ} \mathrm{C}$. Na secagem a $110^{\circ} \mathrm{C}$, observa-se que todas as amostras encontram-se dentro da faixa de variação de resistência à flexão, o que facilita o seu manuseio nas operações de queima.

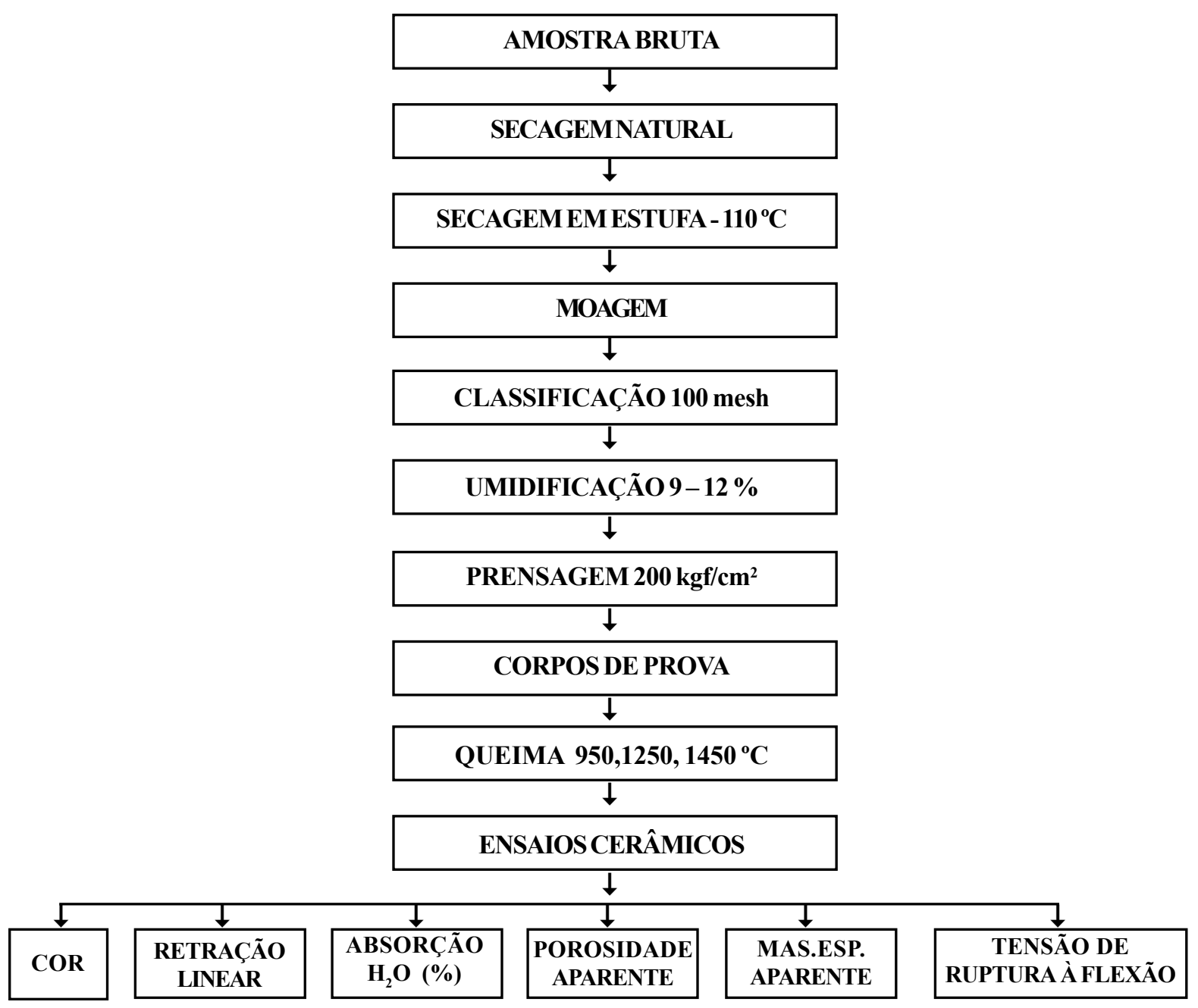

Figura 1: Fluxograma genérico do processamento de argilas do $\mathrm{RN}$ para ensaios cerâmicos.

[Figure 1: Flowchart for processing and characterizing RN clays.] 
A $950^{\circ} \mathrm{C}$, com exceção do ensaio de retração linear, todas as amostras apresentaram variações comparáveis com o padrão de referência e os dados da literatura [5], apresentando valores médios das amostras de 3,31, 17,05, 27,42, 1,10 e 61,95, respectivamente, para a retração linear, absorção de água, porosidade aparente, massa específica aparente e tensão de ruptura à flexão. Nesta temperatura a amostra AM-05 apresentou discrepância, menos nos valores de absorção de água (4,71\%) e porosidade aparente $(9,20 \%)$, com os demais parâmetros de retração linear $(5,31 \%)$, massa específica aparente $\left(1,90 \mathrm{~g} / \mathrm{cm}^{3}\right)$ e tensão de ruptura $\left(169,70 \mathrm{~kg} / \mathrm{cm}^{2}\right)$, o que demonstra ter havido influência de composição mineralógica da amostra.

A $1250{ }^{\circ} \mathrm{C}$ verifica-se que o aumento da temperatura acarretou incrementos nos parâmetros de retração linear, massa específica aparente e tensão de ruptura à flexão, com diminuição da absorção de água e da porosidade aparente, o que já era esperado, pois nesta temperatura, a maioria dos constituintes mineralógicos se fundiram e interligaram as partículas. Nessa temperatura todos os parâmetros estudados são compatíveis com a amostra de referência e dentro dos limites apresentados na literatura.

Na queima a $1450^{\circ} \mathrm{C}$, em média todos os parâmetros estão

Tabela I - Resultados dos ensaios físicos e cerâmicos de corpos de prova queimados a $950{ }^{\circ} \mathrm{C}, 1250{ }^{\circ} \mathrm{C}$ e $1450{ }^{\circ} \mathrm{C}$.

[Table I - Results of physical and ceramic tests of pieces calcined at $950^{\circ} \mathrm{C}, 1250^{\circ} \mathrm{C}$ and $1450{ }^{\circ} \mathrm{C}$.]

\begin{tabular}{|c|c|c|c|c|c|c|}
\hline \multirow{2}{*}{$\begin{array}{l}\text { ARGILAS } \\
\text { ASPECTOS }\end{array}$} & \multicolumn{6}{|c|}{ Variação $950^{\circ} \mathrm{C} * *$} \\
\hline & Cor & $\begin{array}{l}\text { Retração } \\
\text { Linear } \\
(5-12) \%\end{array}$ & $\begin{array}{l}\text { Absorção } \\
\text { de água } \\
(10-55) \%\end{array}$ & $\begin{array}{l}\text { Porosidade } \\
\text { aparente } \\
(19-57) \%\end{array}$ & $\begin{array}{c}\text { Massa } \\
\text { específica } \\
\text { aparente } \\
(1,1-2,1) \mathrm{g} / \mathrm{cm}^{3}\end{array}$ & $\begin{array}{l}\text { Tensão de } \\
\text { ruptura à flexão } \\
(5-245) \mathrm{kg} / \mathrm{cm}^{2}\end{array}$ \\
\hline AM-01* & Creme & 2,10 & 20,70 & 35,80 & 1,72 & 91,00 \\
\hline $\mathrm{AM}-02 *$ & Branco & 3,63 & 24,70 & 35,80 & 1,56 & 8,90 \\
\hline AM-03 & Branco & 1,85 & 20,20 & 32,50 & 1,60 & 20,70 \\
\hline AM04 & Creme-claro & 2,47 & 18,60 & 29,50 & 1,58 & 48,50 \\
\hline AM-05 & Creme-escuro & 5,31 & 4,71 & 9,10 & 1,90 & 169,70 \\
\hline $\begin{array}{l}\text { Variação } \\
1250^{\circ} \mathrm{C} * *\end{array}$ & Cor & $\begin{array}{c}\text { Retração } \\
\text { linear }(5-12) \%\end{array}$ & $\begin{array}{l}\text { Absorção de } \\
\text { água (10-35)\% }\end{array}$ & $\begin{array}{c}\text { Porosidade } \\
\text { aparente }(1-43) \%\end{array}$ & $\begin{array}{c}\text { Massa } \\
\text { específica } \\
\text { aparente } \\
(1,6-2,8) \mathrm{g} / \mathrm{cm}^{3}\end{array}$ & $\begin{array}{c}\text { Tensão de } \\
\text { ruptura } \\
\text { à flexão } \\
(5-480) \mathrm{kg} / \mathrm{cm}^{2}\end{array}$ \\
\hline
\end{tabular}

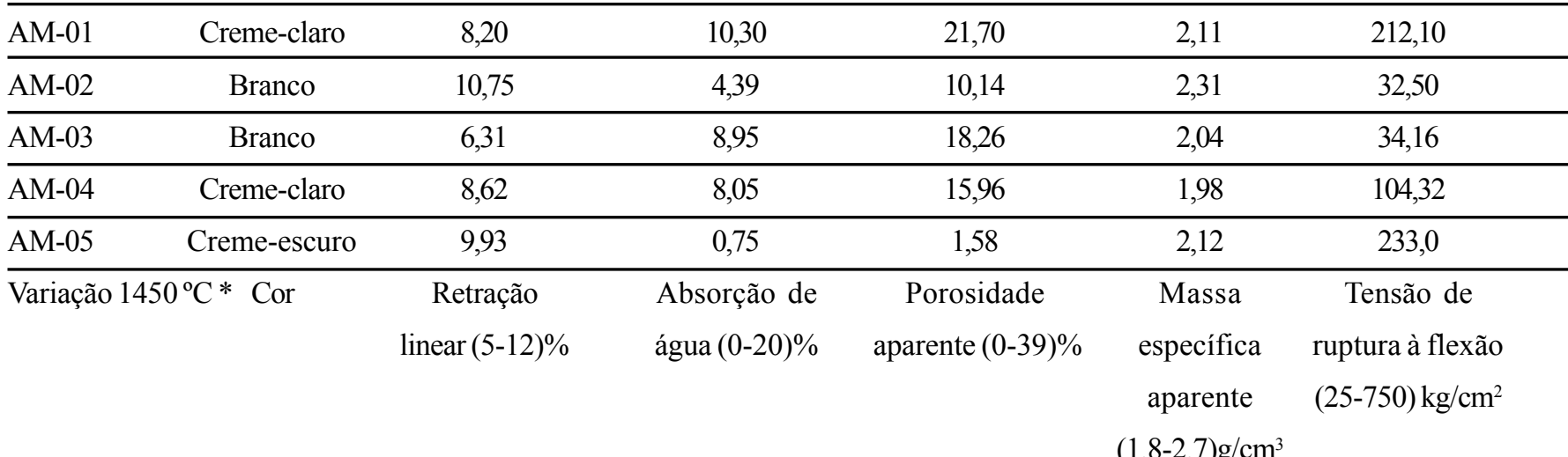

\begin{tabular}{lcccccc}
\hline AM-01 * & Creme-escuro & 11,50 & 1,70 & 4,20 & 2,46 & 309,30 \\
\hline AM-02 & Creme & 14,06 & 5,28 & 11,86 & 2,25 & 29,62 \\
\hline AM-03 & Creme-claro & 6,05 & 9,53 & 19,16 & 2,01 & 2,13 \\
\hline AM-04 & Marron & 12,32 & 0,67 & 1,43 & 2,40 & 210,96 \\
\hline AM-05 & Marron & 5,06 & 1,59 & 2,90 & 1,83 & 16,88 \\
\hline
\end{tabular}

\footnotetext{
* Amostra Referência

** Ref. [5]: Variações de parâmetros cerâmicos de argilas plásticas-refratárias
} 
dentro a faixa de variação da literatura, apresentando valores para mais ou para menos de alguns aspectos em comparação com a amostra referência. Nesta temperatura a amostra AM-05 apresenta em relação a tensão de ruptura, valor da ordem de $16,88 \mathrm{kgf} / \mathrm{cm}^{2}$, inferior aos limites da literatura e cor marron. A amostra AM-04, apresentou cor marron e elevada resistência $\left(210,96 \mathrm{kgf} / \mathrm{cm}^{2}\right)$. Essas variações estão correlacionadas a elevadas temperaturas e seus constituintes mineralógicos.

\section{CONCLUSÕES}

As argilas estudadas podem ser usadas em cerâmica branca, principalmente em processos de queima a $1200-1300^{\circ} \mathrm{C}$.

$\mathrm{Na}$ temperatura de $1250{ }^{\circ} \mathrm{C}$ todas as amostras queimaram com cores variando do creme-claro ao branco, todos os ensaios cerâmicos estão dentro da faixa de variação estudada por P. Souza Santos (1992) para argilas plásticas refretárias e a maioria das amostras são compatíveis aos parâmetros estudados, com a amostra referência

Todas as argilas queimaram com cor variando do branco ao creme-claro nas temperaturas de $950^{\circ} \mathrm{C}$ e $1250^{\circ} \mathrm{C}$. Na queima a $1450^{\circ} \mathrm{C}$ a cor variou do branco ao marrom.

É necessária uma caracterização química e tecnológica para melhor correlacionar os parâmetros estudados. De uma forma geral, todas as argilas estudadas poderão ser usadas em cerâmica branca, dependendo da adequação dos aspectos cerâmicos através de mistura e do processamento térmico para se obter as características finais do produto.

\section{REFERÊNCIAS}

[1] W. L. P. Correia, “Caracterização Química e Mineralógica das Argilas da Baía do Alto Tietê. Contribuição à Geologia e à Aplicação Tecnológica. Parte I: Geologia." Cerâmica 31, 188 (1985) 177. "Parte II: Ensaios Cerâmicos", Cerâmica 33, 204 (1987) 27-46.

[2] A. C. Fernandes e col., "A variação das propriedades de massa cerâmica em função das características físico-químicas, mineralógicas e texturais de argilas da região de Santa Gertrudes - SP”, Cerâmica Industrial 3, 4-6 (1998) 24-29.

[3] M. A. F. Melo, “Caracterização de algumas matérias primas cerâmicas do Rio Grande do Norte para uso em cerâmica branca", Relatório Técnico, FIERN/SENAI/UFRN/ FUNPEC (1998).

[4] F. H. Norton, Introdução à Tecnologia Cerâmica, Edgard Blücher, Editora da Universidade de S. Paulo, S. Paulo, 1973.

[5] P. Souza Santos, Tecnologia de Argilas, vols. I e II, Editora Edgard Blücher, 2 ${ }^{\text {a }}$ Ed., S. Paulo, 1992.

[6] J. V. Souza, P. Souza Santos, "Ensaios preliminares de argilas visando a utilização cerâmica”, Cerâmica 10, 38 (1964) 2.

(Rec. 01/06/00, Ac. 01/11/02) 